ORIGINAL PAPER

\title{
CORRELATION BETWEEN OBESITY AND PROGNOSTIC/PREDICTIVE PARAMETERS WITH EMPHASIS ON THE IMPORTANCE OF LYMPH NODE METASTASES IN PATIENTS WITH INVASIVE BREAST CARCINOMA
}

\author{
Orsolya Hankó-Bauer ${ }^{1}$, Rares Georgescu ${ }^{1}$, Marius F. Coros ${ }^{1}$, Monica Boros ${ }^{2}$, Iulia Barsan ${ }^{3}$, \\ Simona Stolnicu ${ }^{3}$
}

\author{
${ }^{1}$ Department of Surgery, University of Medicine and Pharmacy Targu Mures, Romania \\ ${ }^{2}$ Department of Pathology, County Hospital Oradea, Romania \\ ${ }^{3}$ Department of Pathology, University of Medicine and Pharmacy Targu Mures, Romania
}

\begin{abstract}
We aimed to evaluate whether obese women experience more advanced invasive breast carcinoma (IBC) with a higher number of involved lymph nodes, higher range of axillary lymph node ratio (LNR) and presence and size of extracapsular extension as it may have an impact on prognosis and management. 245 patients diagnosed with IBC were divided into normal weight (NW), overweight (OW) and obese $(\mathrm{OB})$ groups. Patients were divided into high range of LNR (LNR over or equal to 0.2) and low LNR (LNR less than 0.2). The extracapsular extension dimensions were measured on the original slides of each case and grouped into $\leq 1 \mathrm{~mm}$ and $>1 \mathrm{~mm} .84$ patients $(33.07 \%)$ were OW, $72(29.38 \%) \mathrm{OB}$ and $91(37.14 \%) \mathrm{NW} .45 .7 \%$ of cases had macrometastasis in the axillary lymph nodes. NW patients had significantly fewer metastatic lymph nodes $(\mathrm{p}=0.05)$ than in the $\mathrm{OW} / \mathrm{OB}$ groups. There was no statistically significant difference between BMI groups according to the LNR ( $\mathrm{p}=0.66)$. Out of 111 cases with macrometastasis, 58 cases $(52.25 \%)$ had extracapsular extension (ECE) $(11.7 \% \mathrm{NW}, 24.32 \%$ OW and $16.22 \% \mathrm{OB})$. Significantly more OW patients presented extranodal invasion $(\mathrm{p}=0.04)$. We found no statistically significant relationship between the extracapsular extension diameter and BMI groups $(\mathrm{p}=0.1)$.
\end{abstract}

Key words: obesity, lymph node metastasis, breast cancer.

\section{Introduction}

Obesity is a major public health problem in many developed regions in the world, but also in European developing countries including Romania where obesity rates in the adult population have increased in the last decades $[1,2]$. Breast carcinoma is the most frequent form of cancer in women worldwide, as it represents $23 \%$ of all cancers globally, with 1.38 million newly diagnosed cases/year and $28 \%$ of all forms of cancer in Europe [3]. In Romania, breast cancer is a major public health issue, as the incidence has increased steadily during the last decades, from 25/100 000 women in 1988 to $40.14 / 100000$ women in 1996, $50.56 / 100000$ women in 2006 and 61.1/100 000 in 2008, and this incidence continues to increase according to the published studies [4]. The rate of death due to breast cancer has decreased recently by $20 \%$ in 15 European countries (for example, it decreased by $45 \%$ in Iceland), but has remained stationary or even increased in Central and East European countries, and it increased by $17 \%$ in Romania [5]. This is 
due to numerous factors including the socio-economic level of the population, the lack of information, the lack of a national screening program, the lack of specialized medical centers (interdisciplinary units, with few exceptions), but is also due to the increased incidence of obesity.

Obesity has been associated in various studies with an increased risk of breast cancer (but also other non cancer-related deaths), especially in postmenopausal patients, in whom breast cancer is the most common form of cancer in Romania $[6,7]$. Furthermore, obesity on breast cancer diagnosis has been associated with a higher risk of recurrence and inferior survival, including breast cancer-specific survival [8]. Management decisions and survival evaluation in breast carcinomas are based on various prognostic and predictive factors for response to targeted therapies (such as age, tumor size, histological type and grade, molecular status, presence of axillary node metastases). Thus, understanding the relation between host-related factors, such as obesity, and prognostic/predictive factors of the primary breast carcinoma, may have important clinical and prognostic implications.

One of the most important prognostic factors in breast carcinoma is the axillary lymph node status, i.e. the presence or absence of axillary metastases [9, $10,11]$. Disease-free survival and overall survival decrease proportionally with the increase of the number of positive axillary lymph nodes [9]. The number of positive axillary nodes is a strong prognostic factor in breast cancer, but this parameter is affected by variability in nodal staging technique yielding varying numbers of excised nodes. The nodal ratio of positive to excised nodes is an alternative that could address this variability, and previous studies have demonstrated that nodal ratio is a stronger predictor of disease-free survival than total positive nodes excised $[12,13]$. Moreover, the presence of extracapsular extension has been demonstrated to have an impact on survival, and to be associated with higher risk of both mortality and recurrence of disease being recommended the consideration of extracapsular extension in perspectives to be validated and included in the oncologic staging [14, 15].

The aim of this study is, firstly, to evaluate the association between clinical-pathological parameters and obesity, and, secondly, to evaluate whether obese women experience more advanced disease with a higher axillary lymph node ratio and higher stage at the time of diagnosis, as very few papers have addressed this issue so far in the literature [16]. We used body mass index (BMI) as an index and further correlated it with the presence of axillary lymph node metastases (the number of involved lymph nodes, the lymph node ratio (LNR), the presence and diameter of the extracapsular extension).

\section{Material and methods}

\section{Patient selection}

We retrospectively reviewed all the medical records of the patients with invasive breast carcinomas (IBC) from our database consecutively diagnosed between 2012 and 2015 on core biopsy, in whom sentinel lymph node biopsy (SNB) and/or axillary lymph node dissection (ALND) was performed in association with quadrantectomy/mastectomy. These cases originated in a population that had not been previously screened for breast carcinoma because a national screening program concerning this disease is not yet available in Romania. Oncological treatment including chemotherapy (doxorubicin, cyclophosphamide, and paclitaxel or docetaxel), radiotherapy and/or hormonal therapy (tamoxifen or aromatase inhibitors) was standardized for all patients and in accordance with the multidisciplinary tumor board consensus. Patients were divided into a normal weight $(\mathrm{NW})$ group $\left(\mathrm{BMI}<25 \mathrm{~kg} / \mathrm{m}^{2}\right)$, overweight (OW) (BMI $\left.25-29.9 \mathrm{~kg} / \mathrm{m}^{2}\right)$ and obesity (OB) group (BMI $\geq 30 \mathrm{~kg} / \mathrm{m}^{2}$ ) based on the WHO criteria [17]. Details regarding the height and weight to calculate the body index mass (BMI) were retrieved from electronic registration databases. The BMI was calculated as weight divided by the square of height.

\section{Parameter analysis}

In each patient diagnosed with invasive breast carcinoma we assessed the following parameters: age, weight, height, tumor size, histological tumor type and grade, molecular profile, presence of axillary lymph node metastases, the LNR, and presence and size of the extracapsular extension of the lymph node metastasis. The histological type was assessed according to the 2012 WHO classification, and histological grading used the Elston-Ellis system [9, 18]. In this study, the presence of extracapsular extension was defined as extension of tumor cells through the nodal capsule into the peri-nodal adipose tissue and was reported in $\mathrm{mm}$ (millimeters) in every case. In this study, lymph node ratio (LNR) was defined as the number of nodes involved by the tumor divided by the total number of resected lymph nodes during the surgical treatment. Patients were divided into two groups: high range of LNR (LNR over or equal to 0.2 ) and low LNR (LNR less than 0.2).

Hormone receptor (ER - estrogen receptor, PR progesterone receptor), Ki67, and HER2 testing was done by immunohistochemistry according to international recommendations $[19,20,21,22]$. Three-micrometer-thick sections were cut, dried, deparaffinized, and rehydrated following standard procedures. All the sections were subjected to heat-induced an- 
Table I. Specifications of various antibodies used in the study

\begin{tabular}{lclc}
\hline ANTIBODY & ClONE & VeNDOR & Dilution \\
\hline Estrogen receptor & 6F11 & Novocastra & $1: 100$ \\
\hline Progesterone receptor & 312 & Novocastra & $1: 100$ \\
\hline Ki67 & MM1 & Novocastra & $1: 200$ \\
\hline HER2 & CB11 & Novocastra & $1: 200$ \\
\hline
\end{tabular}

tigen retrieval in citrate buffer $(\mathrm{pH} \mathrm{6).} \mathrm{Immunohis-}$ tochemical staining was performed manually, using a NovoLink Polymer Detection System (Leica). Table I reveals the monoclonal antibodies that were used for this study.

In this study, we interpreted tumor foci as ER/ PR positive if expression was observed in at least $1 \%$ of the nuclei of tumor cells (in the total area of the tumor, regardless of staining intensity, with positive internal control), and ER/PR negative when less than $1 \%$ of the tumor cells were positive. $\mathrm{Ki} 67$ index was defined as low (when less than $14 \%$ of all tumor cells' nuclei were positive) or high (equal to or more than $14 \%$ ) by assessing the whole section and recording the overall average score. HER2 expression was scored as follows: 0 (no staining), 1+ (weak incomplete membrane positivity in at least $10 \%$ of the tumor cells), $2+$ (weak/moderate complete membrane positivity in at least $10 \%$ of the tumor cells), and $3+$ (strong complete membrane positivity in at least $30 \%$ of the tumor cells). For statistical analysis, 0 and $1+$ HER 2 scores were considered negative, and scores of $2+$ (confirmed by chromogenic in situ hybridization [CISH] test) and $3+$ were considered positive. In this study, CISH was performed in all cases with a $2+$ score.

We used surrogate definitions of intrinsic subtypes of breast cancer according to Goldhirsch et al. [23] and defined as Luminal A cases with ER and/or PR positive, HER2 negative and Ki67 low $(<14 \%)$ both in tumor and in lymph nodes; as Luminal B proliferative (HER2 negative) (Bp) cases with ER and/or PR positive expression, HER2 negative and Ki67 high; Luminal B (HER2 positive) (Bh) cases which are ER and/or PR positive, any Ki67 and HER2 positive; as HER2 enriched (H) cases with HER2 overexpressed and ER and PR absent; as triple negative (TN) cases with ER, PR and HER 2 negative [23].

\section{Statistical analysis}

Associations between BMI and other prognostic parameters (excluding unknown ones) were analyzed using the chi square test and Fisher's test. All $\mathrm{P}$ values were two-tailed. It was considered statistically significant if $\mathrm{p}<0.05$. Statistical analyses were performed in Graph Pad Prism 6.1 and SPSS.

\section{Results}

The study population comprised 245 consecutive patients with invasive breast carcinoma aged between 27 and 80 years (mean age 58.29 years). Of these, 84 patients $(33.07 \%)$ were OW, 72 (29.38\%) OB and $91(37.14 \%)$ NW. Mean age was 52.81 years in the NW group, 60.38 years in the OW group, and 62.8 in the OB group. However, most of the OW/ OB women were aged $>40(\mathrm{p}=0.0092)$ (Table II).

The size of the primary tumor was grouped in 0-20 mm, 21-50 mm, and over $51 \mathrm{~mm}$ category. In $59.2 \%$ of cases, the patients had tumors between 0-20 mm (54 NW, 59 OW and 39 OB). In the 21-50 $\mathrm{mm}$ group, we detected slightly more $\mathrm{OW}$ and $\mathrm{OB}$ patients than NW (28 NW, $34 \mathrm{OW}$ and $30 \mathrm{OB}$ ). The statistical analysis revealed no significant differences between the tumor diameters in different BMI groups $(\mathrm{p}=0.705)$.

We grouped our patients regarding the histological type of the tumor in no special type of invasive carcinoma (NST type) and other histological types of tumors. One hundred and ninety-eight patients (80.2\%) had NST type tumors (38.4\% NW, 32.3\% OW, and 29.3\% OB); 46 patients were diagnosed with other types of invasive breast cancer $(4.08 \%$ NW; $9.39 \%$ OW and 5.31\% OB). In our series, overweight patients presented a significantly higher rate of other histological types of tumors than the other BMI groups $(\mathrm{p}=0.049)$.

Almost $30 \%$ of all cases $(29.8 \%-73$ patients) had grade 1 tumor $(23.3 \%$ NW, $52.1 \%$ OW and $24.7 \%$ OB), $48.2 \%$ presented grade 2 tumors $(55.8 \%$ NW, $37.5 \% \mathrm{OW}$, and $52.1 \% \mathrm{OB}$ ) and only $22 \%$ had grade 3 tumors (38.9\% NW, 31.5\% OW and 29.6\% OB). In this series, overweight patients had a significantly higher rate of grade 1 tumor compared to other BMI groups, while normal weight patients presented more grade 2 type tumors ( $\mathrm{p}=0.013$ ).

We studied the influence of obesity on the axillary lymph node status, since this is still the most important prognostic factor for breast cancer survival. We grouped our cases in metastatic and non-metastatic lymph nodes highlighted by the histopathological examination after sentinel lymph node biopsy and/or axillary clearance. Over half (54.3\%) of our cases had no metastatic lymph nodes, and in $45.7 \%$ macrome- 
Table II. Correlations between clinico-pathological parameters and obesity

\begin{tabular}{|c|c|c|c|c|c|c|c|c|c|c|}
\hline \multicolumn{2}{|c|}{ Parameter } & \multicolumn{2}{|c|}{$\begin{array}{c}\mathrm{NW} \\
(\mathrm{BMI}<25)\end{array}$} & \multicolumn{3}{|c|}{ OW (BMI 25-29) } & \multicolumn{3}{|c|}{$\mathrm{OB}(\mathrm{BMI}>30)$} & \multirow[t]{2}{*}{$\mathbf{P}$} \\
\hline & & $\mathbf{N}$ & $\%$ & $\mathbf{N}$ & $\%$ & OR $(95 \% \mathrm{CI})$ & $\mathbf{N}$ & $\%$ & OR $(95 \% \mathrm{CI})$ & \\
\hline \multirow[t]{2}{*}{ Age (years) } & $\leq 40$ & 13 & 5.31 & 4 & 1.63 & Referent & 2 & 0.82 & Referent & \\
\hline & $>40$ & 72 & 29.39 & 84 & 34.29 & $\begin{array}{c}3.7917(1.1838 \\
\text { to } 12.1442)\end{array}$ & 70 & 28.57 & $\begin{array}{c}6.3194(1.3757 \\
\text { to } 29.0285)\end{array}$ & 0.005 \\
\hline \multirow[t]{3}{*}{ Tumor size } & $0-20$ & 54 & 22.04 & 52 & 21.22 & Referent & 39 & 15.92 & Referent & \\
\hline & $21-50$ & 28 & 11.43 & 34 & 13.88 & $\begin{array}{l}1.261(0.6725 \\
\text { to } 2.3645)\end{array}$ & 30 & 12.24 & $\begin{array}{c}1.4835(0.7672 \\
\text { to } 2.8688)\end{array}$ & \\
\hline & $>50$ & 4 & 1.63 & 2 & 0.82 & $\begin{array}{c}0.5192(0.0912 \\
\text { to } 2.9571)\end{array}$ & 2 & 0.82 & $\begin{array}{l}2.7692(0.4828 \\
\text { to } 15.8828)\end{array}$ & 0.705 \\
\hline \multirow{2}{*}{$\begin{array}{l}\text { Histological } \\
\text { type }\end{array}$} & NST & 76 & 31.02 & 64 & 26.12 & Referent & 59 & 24.08 & Referent & \\
\hline & others & 10 & 4.08 & 23 & 9.39 & $\begin{array}{c}2.7313(1.2108 \\
\text { to } 6.1610)\end{array}$ & 13 & 5.31 & $\begin{array}{c}1.6746(0.6864 \\
\text { to } 4.0852)\end{array}$ & 0.049 \\
\hline \multirow{3}{*}{$\begin{array}{l}\text { Histological } \\
\text { grade }\end{array}$} & 1 & 17 & 6.94 & 38 & 15.51 & Referent & 18 & 7.35 & Referent & \\
\hline & 2 & 48 & 19.59 & 33 & 13.47 & $\begin{array}{c}0.3076(0.1492 \\
\text { to } 0.6341)\end{array}$ & 37 & 15.10 & $\begin{array}{l}0.728(0.3306 \\
\text { to } 1.6032)\end{array}$ & \\
\hline & 3 & 21 & 8.57 & 17 & 6.94 & $\begin{array}{c}0.3622(0.1536 \\
\text { to } 0.8540)\end{array}$ & 16 & 6.53 & $\begin{array}{l}0.7196(0.2843 \\
\text { to } 1.8214)\end{array}$ & 0.0138 \\
\hline \multirow[t]{3}{*}{ Removed LN } & $1-3$ & 30 & 12.24 & 21 & 8.57 & Referent & 15 & 6.12 & Referent & \\
\hline & $4-9$ & 19 & 7.76 & 23 & 9.39 & $\begin{array}{c}1.7293(0.7580 \\
\text { to } 3.9451)\end{array}$ & 10 & 4.08 & $\begin{array}{l}1.0526(0.3930 \\
\text { to } 2.8192)\end{array}$ & \\
\hline & $10+$ & 37 & 15.10 & 44 & 17.96 & $\begin{array}{c}1.6988(0.8364 \\
\text { to } 3.4506)\end{array}$ & 46 & 18.78 & $\begin{array}{l}2.4865(1.1675 \\
\text { to } 5.2954)\end{array}$ & 0.048 \\
\hline \multirow{2}{*}{$\begin{array}{l}\text { Metastatic } \\
\text { lymph nodes }\end{array}$} & No & 54 & 22.04 & 48 & 19.59 & Referent & 31 & 12.65 & Referent & \\
\hline & Yes & 32 & 13.06 & 40 & 16.33 & $\begin{array}{c}1.4063(0.7671 \\
\text { to } 2.5778)\end{array}$ & 40 & 16.33 & $\begin{array}{l}2.1774(1.1467 \\
\text { to } 4.1344)\end{array}$ & 0.05 \\
\hline \multirow[t]{2}{*}{ LNR } & $<0.2$ & 64 & 26.12 & 64 & 26.12 & Referent & 56 & 22.86 & Referent & \\
\hline & $>0.2$ & 22 & 8.98 & 24 & 9.80 & $\begin{array}{c}1.0909(0.5558 \\
\text { to } 2.1412)\end{array}$ & 15 & 6.12 & $\begin{array}{c}0.7792(0.3689 \\
\text { to } 1.6461) \\
\end{array}$ & 0.66 \\
\hline \multirow[t]{2}{*}{ ECE } & yes & 13 & 11.71 & 27 & 24.32 & $\begin{array}{c}3.8531(1.4322 \\
\text { to } 10.3661)\end{array}$ & 18 & 16.22 & $\begin{array}{l}1.7051(0.6624 \\
\text { to } 4.3894)\end{array}$ & \\
\hline & no & 19 & 17.12 & 13 & 11.71 & Referent & 21 & 18.92 & Referent & 0.04 \\
\hline \multirow{2}{*}{$\begin{array}{l}\text { ECE } \\
\text { diameter }\end{array}$} & $\leq 1 \mathrm{~mm}$ & 5 & 9.26 & 4 & 7.02 & Referent & 7 & 12.96 & Referent & \\
\hline & $>1 \mathrm{~mm}$ & 8 & 14.81 & 21 & 36.84 & $\begin{array}{l}9.531(2.111 \\
\text { to } 43.04)\end{array}$ & 9 & 16.67 & $\begin{array}{c}0.8036(0.1808 \\
\text { to } 3.572)\end{array}$ & 0.1 \\
\hline \multirow{6}{*}{$\begin{array}{l}\text { Molecular } \\
\text { profile }\end{array}$} & A & 12 & 6.94 & 30 & 17.34 & & 16 & 9.25 & & \\
\hline & B-Her2pos & 7 & 4.05 & 5 & 2.89 & & 9 & 5.20 & & \\
\hline & B-Her2neg & 23 & 13.29 & 19 & 10.98 & & 24 & 13.87 & & \\
\hline & TN & 9 & 5.20 & 6 & 3.47 & & 8 & 4.62 & & \\
\hline & $\begin{array}{l}\text { HER2 } \\
\text { enriched }\end{array}$ & 4 & 2.31 & 0 & 0 & & 1 & 0.58 & & 0.012 \\
\hline & Unid & 31 & & 25 & & & 13 & & & \\
\hline
\end{tabular}

$L N$ - lymph node; LNR - lymph node ratio; ECE - extracapsular extension; NW-normal weight; OW-overweight; OB - obese; BMI - body mass index; A - Luminal A cases; B-HER2pos - Luminal B cases; B-HER2neg - Luminal B proliferative cases; TN - triple negative; Unid - unidentified; OR - odds ratio; CI- confidence interval 
tastasis was revealed in the axillary lymph nodes (no cases with micrometastases were documented). NW patients had significantly fewer metastatic lymph nodes $(\mathrm{p}=0.05)$ than in the OW and OB groups.

There was no statistically significant difference between BMI groups according to the $\operatorname{LNR}(\mathrm{p}=0.66)$.

Out of 111 cases with macrometastasis in the axillary lymph nodes, 58 cases $(52.25 \%)$ had extracapsular extension (ECE) (11.7\% NW, 24.32\% OW and $16.22 \% \mathrm{OB})$, and 54 cases were identified without extracapsular extension (Fig. 1). We found statistically significant relations between BMI groups and the presence of ECE in these series: significantly more overweight patients presented extranodal invasion, while normal weight patients were more likely to be without extracapsular extension $(p=0.04)$.

Out of 58 cases which presented ECE, 4 were ruled out of the study because original slides were not accessible for size measurements. In the remaining 54 cases, we measured an average $4.4 \mathrm{~mm}$ ECE diameter (minimum $0.1 \mathrm{~mm}$, maximum $21 \mathrm{~mm}$ ). We grouped our cases with ECE in ECE $\leq 1 \mathrm{~mm}(9.25 \% \mathrm{NW}$, $7.01 \% \mathrm{OW}$ and $12.96 \% \mathrm{OB})$ and ECE $>1 \mathrm{~mm}$ groups (17.81\% NW, 36.84\% OW, $16.66 \%$ OB). We found no statistically significant relations between the extracapsular extension diameter and BMI groups $(\mathrm{p}=0.1)$, but the high value of the odds ratio (9.53) between NW and OW groups suggests that an important proportion of OW patients had larger extracapsular extension.

We identified 173 consecutive patients with invasive breast carcinoma and a complete molecular profile, of whom $55(31.79 \%)$ were NW, 60 (34.68\%) OW, and 58 (33.52\%) OB. Out of the 173 cases, 58 were Luminal A-type, 66 were Luminal B-Her 2 negative-type, 21 were of Luminal B-Her2 positive-type, 5 were of Her 2 positive-type, and 23 were of triple negative-type. Statistical analysis revealed that OW patients presented more likely Luminal A type of breast cancer $(p=0.012)$, while normal weight patients were more frequently Luminal B-Her2 negative (Table II).

\section{Discussion}

Obesity and overweight have an increased incidence worldwide. Almost half of European adults are overweight or obese [24], and more than two-thirds of American women are obese, with an increasing risk of postmenopausal breast cancer [25].

$\mathrm{OB}$ and $\mathrm{OW}$ are associated with different clinical, pathological, and molecular parameters suggesting a poorer prognosis in breast cancer.

Studies confirmed the association between obesity and the age of breast cancer patients. It is considered as an independent adverse prognostic factor for elderly patients [26, 27]. Our study revealed that there is a statistically significant relationship between the pa-

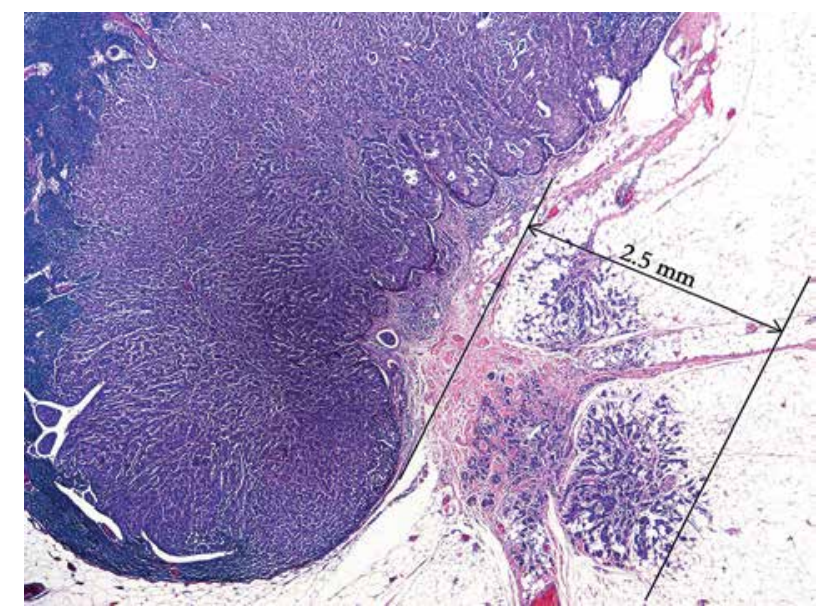

Fig. 1. Lymph node metastasis with extracapsular extension; size measurement of the extracapsular extension defined as extension of tumor cells through the nodal capsule into the peri-nodal adipose tissue was $2.5 \mathrm{~mm}$ (hematoxylin-eosin)

tients' age and their BMI: significantly more OW patients were in the $>40$ age group, while most of the patients in the $<40$ group were NW ( $\mathrm{p}=0.005$ ).

Different studies have revealed that OW and OB are associated with larger tumor diameters $[16,28$, 29]. In our study, OB and OW were also associated with tumors with a diameter of $21-50 \mathrm{~mm}(\mathrm{p}=0.7$, $\mathrm{OR}=1.26,1.48$ ).

Regarding the correlation between the histological type of tumor and obesity, some studies have demonstrated a significant relation between higher BMI and NST histological type [27], while others claim that there is no connection between obesity and histological type of the tumor [29, 30]. In our series, OW and $\mathrm{OB}$ were associated with other histological tumor types than NST ( $p=0.049)$.

Also, several studies showed a strong relation between $\mathrm{OB}, \mathrm{OW}$, and higher histological grade of the primary breast tumor [29, 31, 32]. Contrary to these studies, we found that OW patients had more likely grade 1 tumors $(\mathrm{p}=0.01, \mathrm{OR}=0.307$ ), while normal weight patients in our series had significantly more grade 2 and 3 tumors.

Obesity in association with the molecular profile of breast cancer is a controversial issue in the literature. While several studies indicate that $\mathrm{OB}$ and $\mathrm{OW}$ patients more likely have a TN breast cancer [33, 34], others reveal a significant relationship with ER-positive breast cancer [35]. In our series, OW was strongly associated with Luminal A molecular type ( $\mathrm{p}=0.012)$, which is known to have a better prognosis. These findings may be attributed in part to the increased estrogen production in peripheral fat deposits through androgen aromatization in patients with obesity.

The most important prognostic factor in breast cancer is axillary lymph node involvement. Accord- 
ing to the literature, $\mathrm{OB}$ and $\mathrm{OW}$ are associated with a higher rate of axillary metastatic lymph nodes and higher lymph node ratio $[29,25,28]$. However, no other studies evaluating the relationship between obesity and LNR and/or ECE (the presence of ECE and the size of ECE) have been previously published to the best of our knowledge. Both LNR and ECE are important prognostic parameters as mentioned by international guidelines. This study shows that OW and $\mathrm{OB}$ patients have a significantly higher number of metastatic lymph nodes than NW patients $(\mathrm{p}=$ 0.05 ), and significantly more cases of extracapsular extension $(\mathrm{p}=0.04)$. There was no significant relation between the BMI groups and the LNR or the size of the extracapsular extension.

\section{Conclusions}

In our series, breast cancer patients had a high prevalence of obesity and overweight, mostly over the age of 40 .

$\mathrm{OB}$ and $\mathrm{OW}$ were strongly associated with larger tumor diameter, lower tumor grade, Luminal A-type tumor, higher number of metastatic lymph nodes, and presence of ECE in the metastatic lymph nodes.

Since obese women experience more advanced invasive breast carcinoma, it would be of interest to implement national scale level programs to improve ideal weight maintenance.

We thank Adrian Naznean from the Department of Foreign Language of the University of Medicine and Pharmacy of Tirgu Mures for carefully revising the text of the manuscript.

The authors declare no conflict of interest.

\section{References}

1. Flegal KM, Carroll MD, Ogden CL, et a. Prevalence and trends in obesity among US adults, 1999-2008. JAMA 2010; 303: 235-241.

2. Roman G, Bala C, Creteanu G, et al. Obesity and health-related lifestyle factors in the general population in Romania: a cross sectional study. Acta Endocrinologica (Buc) 2015; 11: 64-71.

3. Ferlay J, Shin HR, Bray F, et al. (eds.). GLOBOCAN $2008 \mathrm{v}$ 1.2. Cancer incidence and mortality worldwide: IARC Cancer Base No. 10, International Agency for Research on Cancer (http://globocan.iarc.fr) Lyon 2008.

4. Anghel R, Minea L, Dediu, et al. Ghidul de management al cancerului mamar; Monitorul Oficial. Partea I, Nr. 608 bis, September 2009.

5. Joergensen LE, Gunnarsdottir KA, C. Lanng C, et al. Multifocality as a prognostic factor in breast cancer patients registered in Danish Breast Cancer Cooperative Group (DBCG) 19962001. Breast 2008, 17: 587-591.

6. Parkin DM, Bray F, Ferlay J, et al. Global cancer statistics, 2002. CA Cancer J Clin 2005; 55: 74-108.

7. Renehan AG, Tyson M, Egger M, et al. Body-mass index and incidence of cancer: a systematic review and meta-analysis of prospective observational studies. Lancet 2008; 371: 569-578.
8. Protani M, Coory M, Martin JH. Effect of obesity on survival of women with breast cancer: systematic review and meta-analysis. Breast Cancer Res Treat 2010; 123: 627-635.

9. Lakhani S, Ellis IO, Schnitt SJ, et al. World Health Organization classification of tumors of the breast. IARC Press; Lyon 2012; 13-77.

10. Perry N, Broeders M, De Wolf C, et al. European Guidelines for Quality Assurance in Breast Cancer Screening and Diagnosis. 4th edition. Office for Official Publications of the European Communities, Luxemburg 2006; 219-313.

11. Rosen PP. Invasive Duct Carcinoma: Assessment of Prognosis, Morphologic Prognostic markers and Tumor Growth Rate. In: Rosen's Breast Pathology. 3rd ed. Lippincot Williams \& Wilkins, Philadelphia 2009; 358-459.

12. Vinh-Hung V, Nguyen NP, Cserni G, et al. Prognostic value of nodal ratios in node-positive breast cancer: a compiled update. Future Oncol 2009; 5: 1585-1603.

13. Martin FT, O'Fearraigh C, Hanley C, et al. The prognostic significance of nodal ratio on breast cancer recurrence and its potential for incorporation in a new prognostic index. Breast $\mathrm{J}$ 2013; 19: 388-393.

14. Nottegar A, Veronese N, Senthil M, et al. Extra-nodal extension of sentinel lymph node metastasis is a marker of poor prognosis in breast cancer patients: A systematic review and an exploratory meta-analysis. Eur J Surg Oncol 2016; 42: 919-925.

15. Drinka E, Allen P, McBride A, et al. Metastatic Tumor Volume and Extranodal Tumor Extension: Clinical Significance in Patients With Stage II Breast Cancer. Arch Pathol Lab Med 2015; 139: 1288-1294.

16. Kaviani A, Neishaboury MR, Mohammadzadeh N, et al. Effects of obesity on presentation of breast cancer, lymph node metastases and patient survival: a retrospective review. Asian Pacific J Cancer Prev 2013; 14: 2225-2229.

17. World Health Organization. Obesity. Preventing and managing the global epidemic. Report of a WHO consultation on obesity. WHO/NUT/NCD/981, WHO, Geneva. 1998.

18. Ellis IO, Elston CW. Histologic grade. In: O'Malley FP, Pinder SE, editors. Breast pathology. Elsevier, Philadelphia 2006; 225-233.

19. Hammond ME, Hayes DF, Dowsett M, et al. American Society of Clinical Oncology/College of American Pathologists guideline recommendations for immunohistochemical testing of estrogen and progester- one receptors in breast cancer. J Clin Oncol 2010; 28: 2784-2795.

20. Hammond ME. ASCO-CAP guidelines for breast predictive factor testing: an update. Appl Immunohistochem Mol Morphol 2011; 19: 499-500.

21. Wolff AC, Hammond ME, Schwartz JN, et al. American Society of Clinical Oncology/College of American Pathologists guideline recommendations for human epidermal growth factor receptor 2 testing in breast cancer. Arch Pathol Lab Med 2007; 131: 18-43.

22. Dowsett M, Nielsen TO, A'Hern R, et al. Assessment of Ki67 in breast cancer: recommendations from the International Ki67 in Breast Cancer working group. J Natl Cancer Inst 2011; 103: 1656-1664.

23. Goldhirsch A, Wood WC, Coates AS, et al. Panel members. Strategies for subtypes--dealing with the diversity of breast cancer: highlights of the St. Gallen International Expert Consensus on the Primary Therapy of Early Breast Cancer 2011. Ann Oncol 2011; 22: 1736-1747.

24. Gallus S, Lugo A, Murisic B, et al. Overweight and obesity in 16 European countries. Eur J Nutr 2015; 54: 679-689.

25. Neuhouser ML, Aragaki AK, Prentice RL, et al. Overweight, Obesity, and Postmenopausal Invasive Breast Cancer Risk: A Secondary Analysis of the Women's Health Initiative Randomized Clinical Trials. JAMA Oncol 2015; 1: 611-621. 
26. Scholz C, Andergassen U, Hepp P, et al. Obesity as an independent risk factor for decreased survival in node-positive high-risk breast cancer. Breast Cancer Res Treat 2015; 151: 569-576

27. Ewertz M, Jensen MB, Gunnarsdóttir KÁ, et al. Effect of obesity on prognosis after early-stage breast cancer. J Clin Oncol 2011; 29: 25-31.

28. Biglia N, Peano E, Sgandurra P, et al. Body mass index (BMI) and breast cancer: impact on tumor histopathologic features, cancer subtypes and recurrence rate in pre and postmenopausal women. Gynecol Endocrinol 2013; 29: 263-267.

29. Haakinson DJ, Leeds SG, Dueck AC, et al. The impact of obesity on breast cancer: a retrospective review. Ann Surg Oncol 2012; 19: 3012-3018

30. Deglise C, Bouchardy C, Burri M, et al. Impact of obesity on diagnosis and treatment of breast cancer. Breast Cancer Res Treat 2010; 120: 185-193.

31. Daling JR, Malone KE, Doody DR, et al. Relation of body mass index to tumor markers and survival among young women with invasive ductal breast carcinoma. Cancer. 2001; 92 720-729.

32. Carmichael AR, Bates T. Obesity and breast cancer: a review of the literature. Breast 2004; 13: 85-92.

33. Eichholzer M, Huang DJ, Modlasiak A, et al. Impact of body mass index on prognostically relevant breast cancer tumor characteristics. Breast Care 2013; 8: 192-198.

34. Pierobon M, Frankenfeld CL. Obesity as a risk factor for triple-negative breast cancers: a systematic review and meta-analysis. Breast Cancer Res Treat 2013; 137: 307-314.

35. Bandera EV, Chandran U, Hong CC, et al. Obesity, body fat distribution, and risk of breast cancer subtypes in African American women participating in the AMBER Consortium. Breast Cancer Res Treat 2015; 150: 655-666.

\section{Address for correspondence}

Rares Georgescu

Department of Surgery

University of Medicine and Pharmacy Targu Mures

Ghoerghe Marinescu no. 1

540103 Targu Mures, Romania

e-mail: breastcancer.reas.tgm@gmail.com 